\title{
AN IMPROVED HIGH VACUUM MERCURY VAPOR PUMP.
}

\author{
By Chas. T. KNIPP.
}

$\mathrm{T}^{\mathrm{H}}$ E diffusion pump of Gaede ${ }^{1}$ has stimulated a number of investigators in this country to enter the field of pump design with the result that several improvements involving new principles have been published. In a recent number of the PHysICAL REVIEW Langmuir ${ }^{2}$ describes an improved mercury vapor pump "characterized by its extreme speed and the high degree of vacuum attainable." The writer of this note being interested for a number of years in the production of high vacua also seized upon this opportunity to aid, if possible, in simplifying the means by which vacua are produced in the research laboratory and submits the following design made wholly of glass as an improved high-vacuum highspeed mercury vapor pump.

The pump complete, except the usual mercury vapor trap, is shown in the figure, which is one third full size. The bulb to be exhausted and trap are fused to $B$, while the tube $E$ is attached to the supporting or rough pump. The mercury vapor rising from the lower bulb, which is heated in a sand or heavy oil bath, streams up through the short tubes $P$ and $O$ and is deflected downward through an annular throat by the umbrella $N$. The issuing mercury vapor at once condenses on the water-cooled surface of the enveloping tube and, as Langmuir ${ }^{3}$ pointed out, the gas that comes from $B$ is forced mechanically downward from the lower edge of $N$ along the cooled surface of the condensing chamber. This accumulated gas is removed through the lat- An improved high eral tubes $b b$, which unite at the top and form the vacuum mercury vapor exhaust tube $E$, all being enveloped by the water pump.

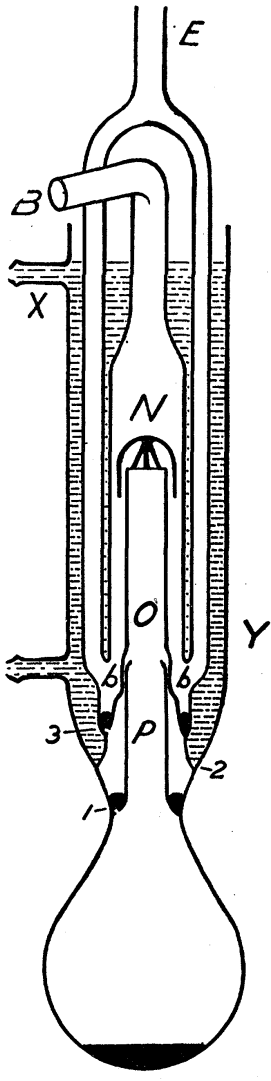

Fig. 1. jacket $X Y$, as shown in the figure. This construction keeps the

1 Ann. Physik, 46, 357, r9I5.

2 Phys. Rev., 8, 48, July, I9r6.

${ }^{3}$ Gen. Elect. Rev., r9, ro6o, Dec., I9r6. 
mercury, which collects at the ring-seal 3 , cool, and thus removes the objection that mercury vapor having an upward velocity would enter the annular condensing chamber. A small opening shown at 3 serves as a valve which allows the accumulated mercury to pass, yet due to surface tension maintains a perfect seal. The short tube $P$ is inserted to shield the hot mercury vapor streaming up from the boiler from condensing on the surfaces at 3. The upper end of $P$ telescopes loosely into the lower end of $O$, while the lower end is secured by the ring-seal $\mathrm{I}$, having also a small valve opening in it through which the mercury passes back into the boiler. By making the upper end of $P$ conical condensed mercury vapor is caught in the annular space thus formed and automatically seals the space $P O$ from the cavity just outside of $P$. The cold mercury collected at the ring-seal 3 , and the adjacent water-jacket, thus have but little opportunity of cooling the hot stream of mercury vapor passing up through $P O$, and, furthermore, the temperature gradient between the ring-seals $\mathrm{I}$ and 2 , and 3 and $b b$ are not abrupt, hence there is no danger of the glass cracking. This construction very much simplifies the glass-blowing, since the tube throughout the process is kept perfectly symmetrical.

In the absence of a convenient means of measuring the pressure within the discharge vessel quickly, the writer has chosen to express the degree of exhaustion in terms of the cathode dark space and the sparking distance at a parallel gap in air. The induction coil used was a Io $\mathrm{cm}$. spark Kohl coil, and the parallel gap was between balls I.75 $\mathrm{cm}$. in diameter. The supporting pump was a Gaede rotary mercury pump backed by a Gaede oil box pump. The mercury was heated in an oil bath by one bunsen burner. The trap beyond $B$ was immersed in liquid air. Mercury vapor pumps are not sensibly operative until the vacuum drawn by the supporting pump is of the order of $\mathbf{I ~} \mathrm{cm}$. Crookes dark space, depending upon the construction of the pump as regards annular throat, etc. Hence the test for speed should not be from atmospheric pressure. The following tests serve to give an indication of the speed attainable.

Test I.-With the discharge vessel fused to $B$ (through a centimeter tube $30 \mathrm{~cm}$. long) having a volume of $270 \mathrm{c.c}$. it required, by repeated trial, 29 minutes to lengthen the dark space from I cm. to $5 \mathrm{~cm}$. equivalent spark in air; while with the mercury vapor pump operative it required but 43 seconds.

Test 2.-With a 6 liter vessel attached by a short large-diameter tube, it required $5 \mathrm{I}$ minutes to range from $\mathrm{I} \mathrm{cm}$. dark space to an equivalent parallel gap in air of $4.65 \mathrm{~cm}$.; which time interval with this pump 
operative was reduced to $2 \frac{1}{2}$ minutes. At the end of another 2 minutes the vacuum was so hard that the $10 \mathrm{~cm}$. Kohl coil was not able to force a discharge.

The advantages of this form of hot blast mercury vapor condensation glass pump may be briefly stated as

I. The symmetrical design simplifies the glass-blowing.

2. Full effectiveness of the hot blast of mercury vapor without sensible loss of heat through a long delivery tube.

3. Effective cooling by a proper placing of water-jacket, ring-seals, and of an internal shielding tube.

4. The use of simple mercury valves for the direct return of the condensed mercury vapor to the boiler.

LABORATORY OF PHYSICS,

UNIVERSITY OF ILLINOIS,

January 15 , I9I 7 . 